\title{
Integration of Cryopreservation and Tissue Culture for Germplasm Conservation and Propagation of Rosa pomifera 'Karpatia'
}

\author{
Ewelina KWAŚNIEWSKA ${ }^{1}$, Ewa DZIEDZIC ${ }^{2}$, Bożena PAWŁOWSKA ${ }^{1 *}$
}

\author{
${ }^{1}$ University of Agriculture in Krakow, Faculty of Biotechnology and Horticulture, Department of Ornamental Plants, \\ 29 Listopada 54,31-425Krakow, Poland; e.kwasniewska@ogr.ur.krakow.pl; ropawlow@cyf-kr.edu.pl ( ${ }^{*}$ correspondingauthor) \\ ${ }^{2}$ University of Agriculture in Krakow, Department of Pomology and Apiculture, \\ 29 Listopada 54, 31-425 Krakow, Poland; ewa@ogr.ur.krakow.pl
}

\begin{abstract}
Cryopreservation is an useful technique for long-term conservation that requires minimal space and maintenance. Germplasm protection of Rosa is important to preserve genetic diversity, to store material for breeding and to expand new research. This study was conducted to develop a droplet vitrification cryopreservation and micropropagation of Rosa pomifera cv. 'Karpatia', whose large hypanthia are characterized by remarkable pro-health properties. Cultures in vitro were stabilized and shoot tips collected from dormant buds served as initial explants. The multiplication of shoots was carried out on MS medium containing benzyladenine. For the droplet vitrification cryopreservation, shoot tips from in vitro cultures were used: small with exposed meristem and large with a meristem covered with leaves, as well as shoot tips from in situ plants, which were collected in winter. Treatment time with plant vitrification solution (PVS2) was also tested (10-30 minutes). From in vitro culture, $32-41 \%$ small explants with exposed meristem survived, but they regenerated at a very low level. The best cryostorage results were obtained for shoot tips from dormant buds and a 20-minute PVS2 treatment: the survival was $84 \%$ and regeneration $73 \%$. During the post-freezing regeneration multiplication index was 2.4 shoots per one multiplication cycle, after cryopreservation and in the control. On half MS medium without growth regulators, $97-99 \%$ of shoots rooted, and all rooted plants have adapted to ex vitro conditions and were planted into the soil. Biometric analyses during shoot multiplication, rooting and acclimatization stages did not reveal any changes compared to the non-cryopreserved samples.
\end{abstract}

Keywords: acclimatization, droplet vitrification, liquid nitrogen, micropropagation, rooting, shoot tips

Abbreviations: BA - N ${ }^{6}$-benzyladenine; $\mathrm{GA}_{3}$ - gibberellic acid; IBA - indole-3-butyric acid; LS - loading solution; PVS2 plant vitrification solution; RS - recovery solution; LN - liquid nitrogen; FeEDDHA - ethylenediamine di-2-hydroxyphenyl acetate ferric; PPFD - photosynthetic photon flux density

\section{Introduction}

Roses are the most important ornamental plants around the world, known as cut flowers, potted plants and ornamental shrubs in urban architecture and open landscaping (Giorgioni, 2015). Several genotypes of roses contain bioactive and prohealth compounds in fruits, flower petals and leaves, and for this reason they are used in food and herbal industry and medicine (Ercisli, 2007; Günes, 2010; Cheikh-Affene et al., 2013). Rosa pomifera (apple rose) (syn. Rosa villosa) 'Karpatia', which has been selected in 1973 in the Institute of Plant Breeding in Bojnice (Slovak Republic) is characterized by a great array of pro-health properties. It is a high-yielding max. 2 $\mathrm{m}$ high shrub, fruits (hypanthia) are large (diameter $1.5-3 \mathrm{~cm}$ ), dark red, containing large amount of pulp with many bioactive compounds easily assimilable by humans: vitamin C $(3,500$ $\mathrm{mg} / 100 \mathrm{~g}$ ), $\mathrm{A}, \mathrm{E}, \mathrm{K}$ and B-group vitamins, abundant macroand microelements, anthocyanins and carotenoids, tannins and organic and fatty acids (Nowak, 2005; Ercisli, 2007). In addition the apple rose contains polyphenols and bioflavonoids (rutin, quercetin) (Sedlák and Paprštein, 2014; Milala et al., 2013).

Cryopreservation involves the storage of biological material in an ultra-low temperature of liquid nitrogen $(\mathrm{LN})\left(-196^{\circ} \mathrm{C}\right)$ and can be used for preservation of roses in gene banks and conservation of biological diversity (Engelmann, 2011). So far cryopreservation procedures have been published for 21 species and varieties of roses. The first processes of germplasm cryopreservation were carried out on pollen (Marchant et al., 1993; Rajasekharan and Ganeshan, 1994). In recent years, buds 
of Rosa canina and Rosa rubiginosa (Pawłowska and SzewczykTaranek, 2014) and Rosa chinensis 'Old Blush' (Le Bras et al., 2014) taken from plants growing in the field (ground) or greenhouse have been introduced into the liquid nitrogen. In both studies, the droplet vitrification method was used and the obtained survival and regeneration was more than $90 \%$ and $80 \%$, respectively.

Most of the published studies on the cryopreservation of roses refer to the in vitro plant material and these are usually explants containing meristem tissue. Lynch et al. (1996) conducted a study regarding the cryopreservation of Rosa multiflora meristems using the encapsulation-dehydration method, yielding 25\% regenerating explants. Pawłowska and Bach (2011) achieved better results using the same method to cryopreserve meristems of Rosa 'New Dawn'. The encapsulation-dehydration technique was also described for the in vitro fragmented explants of $R$. hybrida 'Helmut Schmidt' using TTC (2,3,5-triphenyl-tetrazoliumchloride) to assess the survival (Mubbarakh et al., 2014).

The vitrification method is rarely described for cryopreservation of roses 'Gold Medal', 'Pink Maya', 'Han Hong' and 'Bo' apical meristems (Qiu Zhu et al., 2009) and of Rosa chinensis 'Old Blush' shoot tips (Le Bras et al., 2014). Up to the present the best results in rose cryopreservation have been achieved applying the droplet vitrification method, which uses cryoprotectants and the high thermal conductivity of aluminium foil. Halmagyi and Pinker (2006a, 2006b) used this method to develop a procedure for freezing the shoot tips of wild roses and Rosa × 'Fairy' hybrid, 'Kardinal', 'Maidy', while Pawłowska (2011) and Pawłowska and Szewczyk-Taranek (2015) for shoot tips of Rosa canina, $R$. rubiginosa, $R$. agrestis and $R$. dumalis.

The development of cryopreservation protocol must be usually preceded by the development of micropropagation protocol, even if explants for freezing are not derived from in vitro cultures. The micropropagation allows not only to obtain easily and efficiently cryostorage plant material, but also postcryopreservation regeneration is usually performed with the use of in vitro technique. A number of papers have been published on in vitro micropropagation of roses and they clearly show that the high heterozygosity and the polyploidy of roses is a delaying and limiting reproduction factor, which necessitates distinct studies on each genotype. It is well-known that the most important technique in micropropagation is the meristem proliferation, wherein apical buds or nodal segments harbouring an axillary bud are cultured to regenerate multiple shoots without the callus phase (Pati et al., 2006; Rout et al., 2006; Sedlak and Paprstein, 2014).

The current study was aimed to develop a highly and efficient method of cryopreservation of Rosa pomifera 'Karpatia', a valuable species with pro-health properties, which can be used in gene banks for rose germplasm protection. The objective of the experiments was to compare the size of explants, time of the PVS2 cryoprotectant action, and the origin of explants (in vitro, in situ) on the efficacy of cryopreservation. In addition, the observations were conducted of biometric characteristics of regenerants after cryopreservation and multiplication in vitro, multiplication and shoots rooting plant acclimatization, until to their introduction in the field.

\section{Materials and Methods}

\section{Plant material for in vitro culture and shoot multiplication}

The initial plant material (vegetative auxiliary buds) of Rose pomifera 'Karpatia' obtained from the pomological collection of the Department of Pomology and Apiculture in Garlica Murowana (GPS 50.140634, 19.930046) was surface disinfected with $70 \%$ ethanol for $1 \mathrm{~min}$ followed by $10 \%$ calcium hypochlorite solution for $10 \mathrm{~min}$. After rinsing with sterile distilled water, the buds were cultured on MS medium (Murashige and Skoog, 1962) solidified with 0.7\% (w/v) Difco Bacto Agar with 3\% sucrose, $\mathrm{pH}$ was adjusted to 5.7 before autoclaving. Initial medium contained BA (6-benzylaminopurine) at a concentration of $4.44 \mu \mathrm{M}$. Cultures were maintained in a 16-hour photoperiod at PPFD $30 \mu \mathrm{mol} \mathrm{m} \mathrm{m}^{-2} \mathrm{~s}^{-1}$ (Philips TL-D 36W/54), at 23/25 $\pm 1{ }^{\circ} \mathrm{C}$ (night/day) and $70 \%$ relative humidity in the growth room.

The micropropagation experiment was performed on stabilized auxiliary shoot culture (after six months of culture in vitro). MS medium was tested with the addition of IBA (indole3-butyric acid) at a concentration of $0.49 \mu \mathrm{M}$ and BA at concentrations of 3.11 or $6.66 \mu \mathrm{M}$. The external conditions were the same as during the initiation of cultures.

The observations of the effectiveness of surface disinfection were conducted and the percentage of explants regenerating shoots was determined. During the multiplication, after each passage, multiplication index (number of new shoots in a 4-week cycle per one shoot), number of leaves per rosette, increase of fresh biomass per plantlets and dry mass content were calculated.

\section{Plantmaterial for cryopreservation}

For cryopreservation, shoot tips were used collected both from in vitro cultures and from in situ plants, the same that were used for in vitro culture initiation.

Explants in vitro were taken from the top of the shoots propagated on MS medium with $0.49 \mu \mathrm{M}$ IBA and $3.11 \mu \mathrm{M}$ BA (Fig. $1 \mathrm{~A})$. Two sizes of explants were isolated and prepared: $\mathrm{L}$ large shoot tips (meristem covered by leaves, $4 \mathrm{~mm}$ ) and $\mathrm{S}$ - small shoot tips (leaves removed, primordia left, exposed meristem 0.2 $\mathrm{mm}$ ), which for technical reasons were cut out with a $2 \mathrm{~mm}$ fragment of the shoot (Fig. 1 C,D)

In situ shoot tips were isolated from dormant buds of one-yearold shoots (Fig. 1 B) in February. The buds were cut in the middle section of the shoots and disinfected with 70\% ethanol for $30 \mathrm{~s}$. Isolation involved removing the leaves, leaving two primordia and exposed meristem of approx. $0.2 \mathrm{~mm}(S)$, which were cut off with a $1-2 \mathrm{~mm}$ piece of shoot (Fig. $1 \mathrm{E}$ ).

\section{Cryopreservation}

The explants were cryopreserved using the droplet vitrification method according to Pawłowska and Szewczyk-Taranek (2014). First shoot tips were kept in a medium with $2 \mathrm{M}$ glycerol and 0.4 M sucrose (loading solution - LS) for $20 \mathrm{~min}$, and were subsequently treated with PVS2 cryoprotectant (30\% glycerol, $15 \%$ ethylene glycol, $15 \%$ DMSO, $0.4 \mathrm{M}$ sucrose and $100 \% \mathrm{MS}$ ) $(10,20$ or $30 \mathrm{~min})$. Before immersion in liquid nitrogen (LN), shoot tips were placed in a drop of PVS2 (plant vitrification solution) on aluminium foil strips. Thawing was carried out in a liquid medium containing $100 \% \mathrm{MS}$ and $1.2 \mathrm{M}$ sucrose (recovery solution - RS) for $20 \mathrm{~min}$. For in situ explants, 0.2\% sodium 



Fig. 1. Rosa pomifera 'Karpatia' explants for cryopreservation: donor plants from in vitro (A) and dormant buds from in situ plant (B), bar $-10 \mathrm{~mm}$; small excised shoot tips with exposed meristem from in vitro (C) and in situ (E), large excised shoot tips with covered meristem from in vitro culture (D) (arrows indicate meristems), bar $-1 \mathrm{~mm}$

hypochlorite was added to this solution and at the end the explants were rinsed in sterile water. Afterwards all the explants were also maintained on media with $50 \%$ MS, $0.3 \%$ sucrose and $0.5 \%$ agar for $24 \mathrm{~h}$, in the dark. Survival rate was determined 10-14 days from thawing and presented in \% of explants that were green and developed (Fig. 2A).

\section{Post-cryopreservation regeneration}

The growth rate (\% of the explants forming shoots) was determined after four weeks (Fig. 2 B). All the small in situ shoot tips of $R$. pomifera 'Karpatia' that regenerated were transferred to the rose multiplication medium (Pawłowska, 2011) containing $100 \% \mathrm{MS}$, 3\% sucrose, FeEDDHA $20 \mathrm{mg} \mathrm{dm}^{-3}$, supplemented with $1 \mu \mathrm{M} \mathrm{BA}$ and $1.5 \mu \mathrm{M} \mathrm{GA}_{3}$ (gibberellic acid), and were maintained in the dark during the first week; PPFD was gradually increased to $30 \mu \mathrm{M} \mathrm{m}^{-2} \mathrm{~s}^{-1}$ after the second week. The developed shoots were propagated on the same medium for 12 weeks (Fig. 2 $\mathrm{C}$ ), newly developed shoots were excised and subcultured on a fresh medium and shoots were transferred three times.

The index of multiplication and number of leaves per shoot was calculated during multiplication.

The rooting stage was conducted on a 50\% MS medium without growth regulators for six weeks (Fig. 2 D). The cultures were performed under the same conditions as in multiplication.
The biometrical observation after six weeks of rooting involved: number of rooted plants, shoot height, number of leaves per shoot, number of roots per shoot and average length of roots. For acclimatization, the agar residues were washed off of the plantlets, and longer roots were cut short to a length of $25 \mathrm{~mm}$. Plants were immersed in a $0.1 \%$ Topsin M 500 SC fungicide solution and planted in plastic containers filled with TS2 substrate (KlasmannDeilmann), $\mathrm{pH}$ 6.0, mixed with sand in a 3:1 ratio. The plantings were covered with a polypropylene transparent film to maintain high humidity (85\%). Containers were kept for six weeks in an acclimatization chamber at a temperature of $22^{\circ} \mathrm{C}$, under artificial light 12/12h (day/night). During the acclimatization, the plants were wet and protected against gray mould (Botrytis cinerea) by using Topsin M 500 SC and Bravo 500 SC (0.1\%). After six weeks of acclimatization (Fig. 2E), roses were separately planted to $9 \mathrm{~cm}$ containers filled with TS2 substrate and transferred to the greenhouse $\left(18 / 23 \pm 2{ }^{\circ} \mathrm{C}\right.$ (night/day) for three month (Fig. $2 \mathrm{~F}$ ). Before winter, roses were cut and placed at $+4^{\circ} \mathrm{C}$ for five winter months. In the spring, roses will be planted in the pomological collection.

After six weeks of acclimatization, the percentage of acclimatized plants (developing new leaves and shoots) was calculated, and the biometrical observations were performed (number of main and lateral shoots, plant height, number of main and lateral roots and average length of the root). 

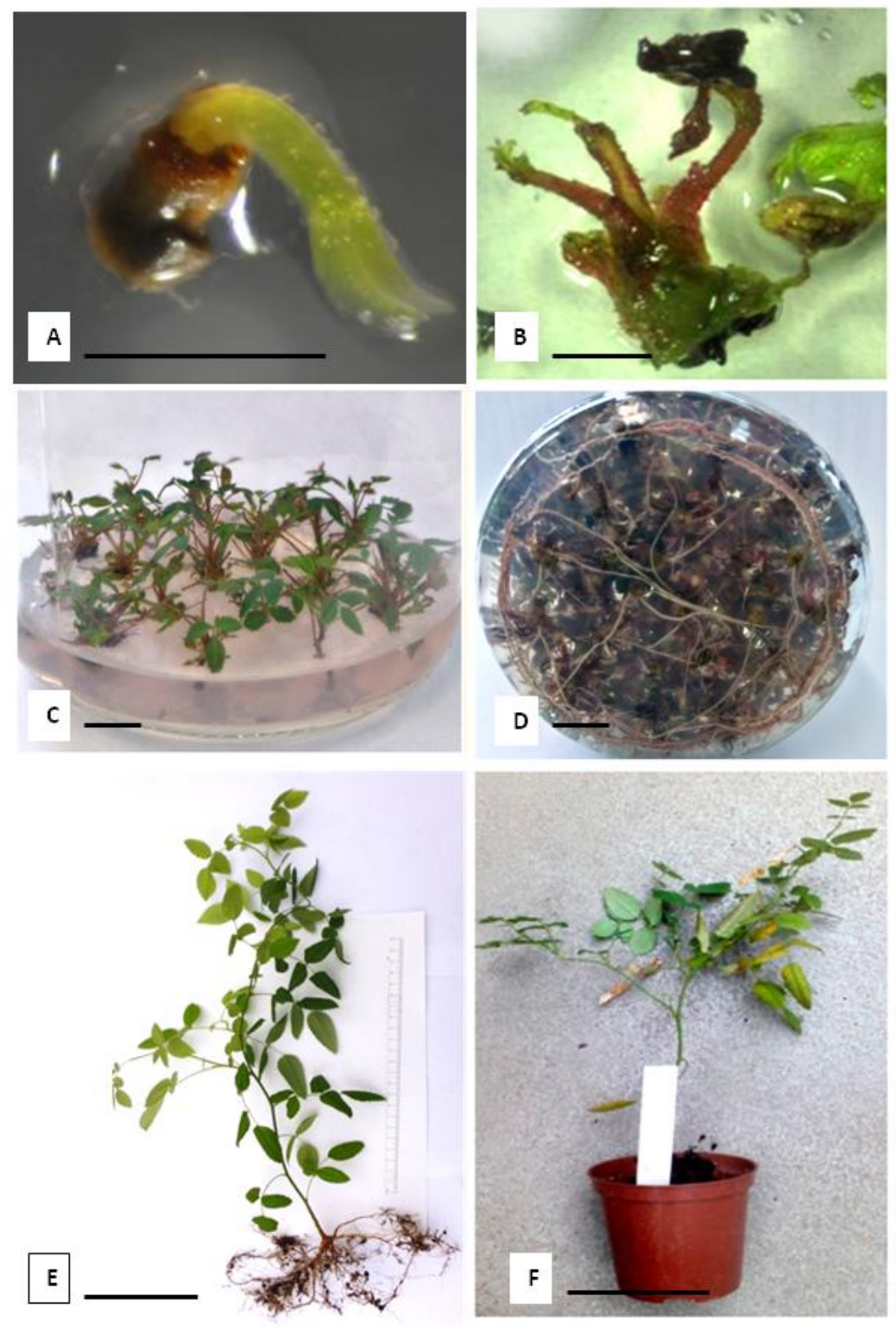

Fig. 2. Rosa pomifera 'Karpatia' post-cryopreservation regeneration. Shoot tip survival on $12^{\text {th }}$ day (A) and $4^{\text {th }}$ week (B) after thawing, bar $-5 \mathrm{~mm}$; rose shoots multiplication (12 week after thawing) and in vitro rooted plants (D), bar - $10 \mathrm{~mm}$; plant after six weeks of acclimatization (E), potted plant after wintering in the greenhouse and before planting into the soil (F), bar - 100 $\mathrm{mm}$

\section{Statisticalanalysis}

The micropropagation of shoots in each combination consisted of five replicates, five explants each. During cryopreservation, each combination had three replicates in every 15-20 shoot tips. During the post-cryopreservation, experiments were performed in five replicates, ten regenerants each. All experiments were repeated 2-3 times and means were used in statistical analysis. The results of the experiments were statistically analysed using analysis of variance (ANOVA) and Statistica software (StatSoft Inc., v. 12, USA); the means were compared by Duncan's test, $\alpha \leq 0.05$.

\section{Results and Discussion}

During the initiation of in vitro cultures of Rosa pomifera 'Karpatia', the method of surface disinfecting of dormant buds with a $10 \%$ solution of calcium hypochlorite for 10 min was effective for all explants and no bacterial or fungal infections were detected. More than $75 \%$ explants placed on the medium regenerated shoots, of which in vitro auxiliary shoot cultures were established and maintained (data not shown). Sedlák and Paprštein (2014), during the initiation of in vitro cultures of rose of the same genotype, obtained satisfactory results using a $0.5 \% \mathrm{NaClO}$ for one minute, and surface disinfection efficiency of the buds was $96.7 \%$ and regeneration was $75 \%$. The present results concerning the shoot micropropagation stage are shown in Table 1. The increased concentration of BA in the medium resulted in a higher index of multiplication, a lower number of leaves per shoot, and a higher increase of shoot biomass. Pati et al. (2006) indicated that BA was the most frequently used cytokinin for the multiplication of rose 
212

Table 1. Effect of BA cytokinin concentration on shoot multiplication of $R$. pomifera 'Karpatia' in vitro culture

\begin{tabular}{ccccc}
\hline $\begin{array}{c}\text { Concentration of } \\
\mathrm{BA}(\mu \mathrm{M})\end{array}$ & Index of multiplication & $\begin{array}{c}\text { Number of leaves per } \\
\text { one rosette }\end{array}$ & $\begin{array}{c}\text { Increase of fresh biomass } \\
(\mathrm{mg}) \text { per one plantlet }\end{array}$ & Dry mass of shoots $(\%)$ \\
\hline 3.11 & $2.84 \pm 0.6 \mathrm{a}^{*}$ & $5.6 \pm 1.2 \mathrm{~b}$ & $58.5 \pm 12.3 \mathrm{a}$ & $15.40 \pm 3.8 \mathrm{a}$ \\
\hline 6.66 & $3.80 \pm 0.5 \mathrm{~b}$ & $3.9 \pm 0.9 \mathrm{a}$ & $220.3 \pm 29.8 \mathrm{~b}$ & $19.19 \pm 5.1 \mathrm{a}$ \\
\hline${ }^{*}$ Means for the examined attributes followed by the same letter do not differ significantly at $\alpha=0.05$, according to the Duncan's test &
\end{tabular}

Table 2. Morphometrical characteristic of $R$ pomifera 'Karpatia' post-cryopreservation regenerants during shoot propagation and rooting in vitro, depending on the shoot tip treatment time with PVS2 before freezing

\begin{tabular}{|c|c|c|c|c|c|c|c|}
\hline \multirow[b]{2}{*}{$\begin{array}{c}\text { PVS2 } \\
\text { treatment } \\
\text { time }(\min )\end{array}$} & \multicolumn{2}{|c|}{ Shoot multiplication } & \multirow[b]{2}{*}{$\begin{array}{c}\text { Rooted plants } \\
(\%)\end{array}$} & \multicolumn{4}{|c|}{ Rooting } \\
\hline & $\begin{array}{c}\text { Index of } \\
\text { multiplication }\end{array}$ & $\begin{array}{c}\text { Number of leaves } \\
\text { per shoot }\end{array}$ & & $\begin{array}{l}\text { Height of } \\
\text { shoots } \\
(\mathrm{cm})\end{array}$ & $\begin{array}{c}\text { Number of leaves } \\
\text { per shoot }\end{array}$ & $\begin{array}{c}\text { Number of roots } \\
\text { per shoot }\end{array}$ & $\begin{array}{l}\text { Length of roots } \\
(\mathrm{cm})\end{array}$ \\
\hline Control $^{* *}$ & $2.3 \pm 0.50 a^{*}$ & $4.7 \pm 0.1 \mathrm{a}$ & $97 \pm 1.0 \mathrm{a}$ & $1.2 \pm 0.03 \mathrm{a}$ & $9.5 \pm 0.10 a$ & $1.2 \pm 0.65 \mathrm{a}$ & $18.0 \pm 1.21 \mathrm{~b}$ \\
\hline 20 & $2.4 \pm 0.48 \mathrm{a}$ & $4.9 \pm 0.1 \mathrm{a}$ & $99 \pm 1.0 \mathrm{a}$ & $1.0 \pm 0.05 \mathrm{a}$ & $12.0 \pm 0.02 b$ & $5.4 \pm 2.21 b$ & $8.9 \pm 2.69 \mathrm{a}$ \\
\hline 30 & $2.3 \pm 0.39 a$ & $5.3 \pm 0.45 a$ & $97 \pm 1.0 \mathrm{a}$ & $2.2 \pm 1.92 \mathrm{a}$ & $12.1 \pm 0.10 b$ & $5.6 \pm 2.58 \mathrm{~b}$ & $7.6 \pm 3.22 \mathrm{a}$ \\
\hline
\end{tabular}

${ }^{*}$ Means for the examined attributes followed by the same letter do not differ significantly at $\alpha=0.05$, according to the Duncan's test

${ }^{* *}$ Regenerants after in vitro without cryopreservation

Table 3. Morphometrical characteristic of $R$ pomifera 'Karpatia' post-cryopreservation regenerants during ex vitro after six weeks of acclimatization, depending on the shoot tip treatment time with PVS2 before freezing

\begin{tabular}{|c|c|c|c|c|c|c|c|}
\hline $\begin{array}{c}\text { PVS2 } \\
\text { treatment } \\
\text { time }(\mathrm{min})\end{array}$ & $\begin{array}{c}\text { Acclimatized } \\
\text { plants } \\
(\%)\end{array}$ & $\begin{array}{c}\text { Number of } \\
\text { main } \\
\text { shoots }\end{array}$ & $\begin{array}{c}\text { Number of lateral } \\
\text { shoots }\end{array}$ & $\begin{array}{l}\text { Height of shoots } \\
\qquad(\mathrm{cm})\end{array}$ & $\begin{array}{l}\text { Number of } \\
\text { main roots }\end{array}$ & $\begin{array}{l}\text { Number of } \\
\text { lateral roots }\end{array}$ & $\begin{array}{l}\text { Length of roots } \\
(\mathrm{cm})\end{array}$ \\
\hline Control $^{* *}$ & $100 \pm 0 a^{*}$ & $1.0 \pm 0 \mathrm{a}$ & $0.8 \pm 0.4 \mathrm{a}$ & $29.7 \pm 5.3 \mathrm{a}$ & $3.4 \pm 1.5 \mathrm{a}$ & $30.8 \pm 8.6 \mathrm{a}$ & $18.1 \pm 6.2 \mathrm{a}$ \\
\hline 20 & $100 \pm 0 \mathrm{a}$ & $1.0 \pm 0 \mathrm{a}$ & $0.6 \pm 0.5 \mathrm{a}$ & $33.9 \pm 9.1 \mathrm{a}$ & $3.3 \pm 1.6 \mathrm{a}$ & $29.4 \pm 9.4 \mathrm{a}$ & $18.8 \pm 7.4 \mathrm{a}$ \\
\hline 30 & $100 \pm 0 a$ & $1.0 \pm 0 \mathrm{a}$ & $0.3 \pm 0.5 \mathrm{a}$ & $25.8 \pm 8.5 \mathrm{a}$ & $3.5 \pm 1.5 \mathrm{a}$ & $30.3 \pm 8.8 \mathrm{a}$ & $16.0 \pm 5.1 \mathrm{a}$ \\
\hline
\end{tabular}

* Means for the examined attributes followed by the same letter do not differ significantly at $\alpha=0.05$, according to the Duncan's test

${ }^{*}$ Regenerants after in vitro without cryopreservation

shoots and provided high effectiveness. Similarly, Sedlák and Paprštein (2014) argued that the BA cytokinin was more appropriate for the multiplication of Rosa pomifera 'Karpatia' shoots compared to $2 \mathrm{iP}$ or thidiazuron.

Cryopreservation using the droplet vitrification method conducted for small and large shoot tips of 'Karpatia' rose isolated from in vitro cultures showed that the size of explants had an impact on the survival and regeneration after thawing. However, PVS2 treatment time did not affect these characteristics (Fig. 3A, B). Small explants exhibited more than two fold higher survival ratio (32-41\%). Only $10-18 \%$ of large explants survived the regeneration, but none of them regenerated further. Small rose shoot tips (apical meristems with 2-3 primordia) are approximately $0.1 \mathrm{~mm}$ in length, and they are at a constant risk of mechanical damage both during isolation and pretreatment. However, as confirmed by most studies, only cryopreservation of shoot tips with 2-3 primordia and exposed meristem was successful in $R$. chinensis 'Old Blush', R. canina and R. rubiginosa (Le Brass et al., 2014; Pawlowska and Szewczyk-Taranek, 2014; 2015). The study of Barraco et al. (2011) indicated that uncovering the meristem is a prerequisite for efficient cryopreservation of Limonium serotinum shoot tips containing at most one or two leaf primordia. In banana plants, even the leaf primordia had to be removed, which ensures better effect of cryoprotectant solutions, which are applied before placing in LN (liquid nitrogen), and facilitates regeneration after thawing (Panis $e t$ al., 2005). Only a few studies performed successful cryopreservation using large explants, where meristem was covered by leaves. Halmagyi and Pinker (2006a) obtained 92\% rate of regenerating 3-4 mm shoot tips of Rosa $\times$ bybrida 'Kardinal', which could be related to individual characteristics of this genotype.

In the present experiment, small shoot tips from in vitro cultures, which survived cryopreservation, regenerated very poorly only at a level of few percent (Fig. 3B). However, the use of the dormant buds of in situ plants for collecting the explants with exposed meristems for cryopreservation provided great results (Fig. 4A). The survival rate in this case was about twice as high as in the in vitro explants, and the best results were achieved for the treatment with PVS2 cryoprotectant solution for 20 and $30 \mathrm{~min}(75-84 \%)$, while the best regeneration showed the explants after 20 min of PVS2 treatment (73\%) (Fig. 4B). This PVS2 treatment time in the previously published studies using the droplet vitrification method was also most effective. Pawłowska and Szewczyk-Taranek (2014) showed that a 40-min exposure to PVS2 visibly lowered the regeneration of shoot tips of in situ dog roses. It is consistent with the results by Halmagyi and Pinker (2006a) on in vitro apical buds of rose varieties 'Cardinal', 'Fairy' and 'Maidy', which demonstrated that the PVS2 treatment longer than 20 min was toxic and reduced regeneration. Le Bras et al. (2014) tested even an 80-min LS (loading solution) treatment in $R$. sinensis 'Old Blush', nevertheless it did not improve the survival of the explants compared to a 20-min treatment.

PVS2 is still most effective for protection of dicotyledonous and monocots (Sakai et al., 1990; Souza et al., 2016; Maślanka et al., 2016). About 50\% of the explants Malus $\times$ domestica Borkh. 'Golden Delicious', treated with PVS2 for $40 \mathrm{~min}$ survived after immersion in liquid nitrogen (Poisson $e t$ al., 2016). Droplet-vitrification conservation of different genotypes of pineapple gave the best survival for $45 \mathrm{~min}$ treatment time of PVS2.

Our results confirm that droplet vitrification cryopreservation is highly efficient for rose shoot tips survival rate and regeneration. Pawłowska and Bach (2011) achieved worse results using encapsulation-dehydration method to cryopreserve meristems of Rosa 'New Dawn'; 33\% of the apical 

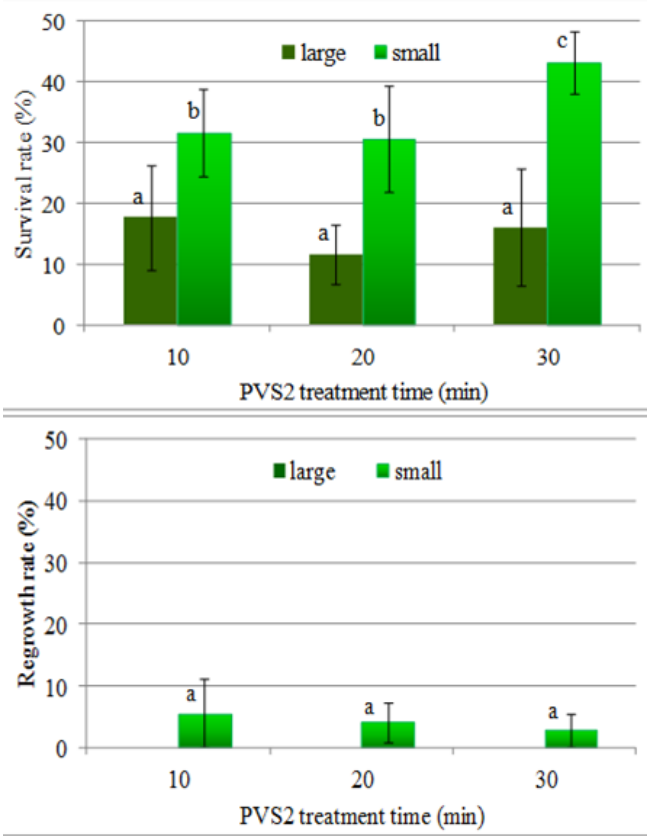

Fig. 3. Effect of size of in vitro shoot tips and PVS2 treatment time on survival (A) and regrowth rate (B) of Rosa pomifera 'Karpatia' after cryopreservation. * Means for the examined attributes followed by the same letter do not differ significantly at $\alpha=0.05$, according to the Duncan's test

meristems and $69 \%$ of the lateral meristems survived cryopreservation. Qiu Zhu et al. (2009) subjected to cryopreservation apical meristems of four varieties: 'Gold Medal', 'Pink Maya', 'Han Hong' and 'Bo', obtaining the best result only for 'Gold Medal' (55.3\% survival rate). Application of vitrification method for the shoot tips of Rosa chinensis 'Old Blush' resulted in a not high regeneration rate $43.3 \%$ (Le Bras et al., 2014). Similarly using the same method Liu et al. (2015) obtained 40\% regeneration of Rosa chinensis 'Old Blush' explants, after 60 min PVS2 treatment time.

The morphometrical analyses are the easiest and inexpensive methods and are often the first stage of testing the post-cryopreservation regenerants for genetic fidelity (Kaity et al., 2009). In this experiment, rose shoot tips developed auxiliary buds after cryopreservation and then they were multiplied in vitro on Pawlowska (2011) rose regeneration medium. Biometric examination during shoot multiplication stage did not reveal any changes in the index of shoot multiplication and number of leaves per shoot compared to the non-cryopreserved samples (Table 2). However, during the last stage of the clonal propagation - rooting - shoots regenerated after cryopreservation formed more and shorter roots; they also had more leaves than the control plants. The observations, performed after the acclimatization of plants, showed no morphological differences between regenerants - all the plants have acclimatized (Table 3). To date, there are few studies concerning the evaluation of the quality of the plants regenerated after cryopreservation, and only one in case of the genus Rosa. Pawłowska and Szewczyk-Taranek (2015) noted the stability of regenerants after cryopreservation, as measured phenotypically. Several authors detected no phenotypic changes in cryopreserved plants (papaya, banana, iris, wasabi) after further culture growth and the obtained regenerants were
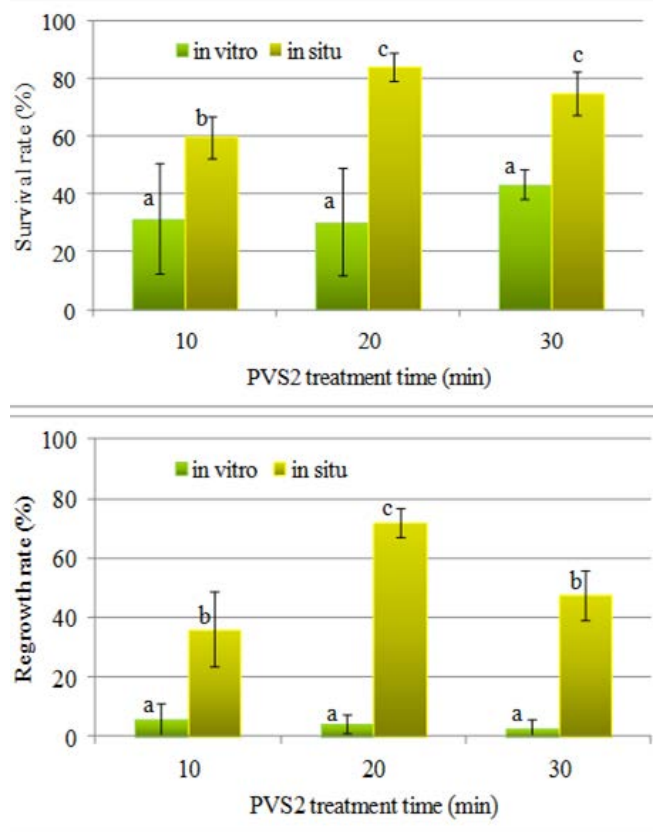

Fig. 4. Effect of explants origin and PVS2 treatment time on survival (A) and regrowth rate (B) of Rosa pomifera 'Karpatia' small shoot tips after cryopreservation. ${ }^{*}$ Means for the examined attributes followed by the same letter do not differ significantly at $\alpha=0.05$, according to the Duncan's test

true-to-type (Harding, 2004; Kaity et al., 2009; Jevremović et al., 2011; Matsumoto et al., 2013; Agrawal et al., 2014).

In addition to highly efficient cryopreservation method, the present study developed a clonal propagation method of Rosa pomifera 'Karpatia' reaching an index of shoot multiplication at the level of 2.3-3.8, a high percentage of rooted shoots (97-99\%) and $100 \%$ successful acclimatization. In the only work on micropropagation of Rosa pomifera 'Karpatia' published so far, Sedlák and Paprštein (2014) obtained similar results in the proliferation of shoots and acclimatization, while weaker outcomes in rooting, despite the use of auxin in the medium.

\section{Conclusions}

The droplet vitrification cryopreservation is a useful technique for the protection of germplasm of Rosa pomifera 'Karpatia'. Integration of cryopreservation and tissue culture for germplasm conservation was favourable, because the regeneration of plants taken out from $\mathrm{LN}$ was carried out in the in vitro culture. MS medium, containing BA $(1-6.66 \mu \mathrm{M})$ stimulated shoot proliferation, and half MS medium without plant growth regulators was used for efficient rooting. In vitro and post-cryopreservation regenerants acclimatized in $100 \%$.

\section{Acknowledgements}

This work was supported by the Polish Ministry of Higher Education DS 3500.

\section{References}

Agrawal A, Sanayaima R, Singh R, Tandon R, Verma S, Tyagi RK (2014). Phenotypic and molecular studies for genetic stability assessment of cryopreserved banana meristems derived from field and in vitro explant 
214

sources. In vitro Cellular Developmental Biology Plant 50:345-356.

Barraco G, Sylvestre I, Iapichino G, Engelmann F (2011). Cryopreservation of Limonium serotinum apical meristems from in vitro plantlets using droplet vitrification. Scientia Horticulturae 130:309-313.

Cheikh-AffeneZB, Haoual F, Trabelsi N, Boulaaba M, Ksouri R, HarzallahSkhiri F (2013). Pomological description and chemical composition of rose hips gathered on four Rosa species section Caninae growing wild in Tunisia. International Journal of Agricultural Science and Technology $1(3): 43-50$.

Engelmann F (2011). Use of biotechnologies for the conservation of plant biodiversity. In vitro Cellular Developmental Biology Plant 47:5-16.

Ercisli S (2007). Chemical composition of fruits in some rose (Rosa spp.) species. Food Chemistry 104(4):1379-1384.

Giorgioni ME (2015).Plant growth and flowering trend of landscaping roses under low maintenance and xeric conditions. Acta Horticulturae 1064:279-284.

Günes M (2010) Pomological and phenological characteristics of promising rose hip (Rosa) genotypes. African Journal of Biotechnology 9(38):6301-6306.

Halmagyi A, Pinker I (2006a). Plant regeneration from Rosa shoot tips cryopreserved by a combined droplet vitrification method. Plant Cell Tissue Organ Culture 84:145-153.

Halmagyi A, Pinker I (2006b). Cryopreservation of Rosa shoot tips: importance of preculture conditions. Acta Horticulturae 725:351-356.

Harding K (2004). Genetic integrity of cryopreserved plant cells: a review. CryoLetters 25:3-22.

Jevremović S, Bohanec B, Lambardi M, De Carlo A, Benelli C, Angelina S (2011). Clonal fidelity of Iris plants regenerated after cryopreservation. Cryopreservation Symposium, COST Action 871 Cryopreservation of crop species in Europe, Final meeting, Angers, France, February 8-11:4043.

Kaity A, Ashmore SE, Drew RA (2009). Field performance evaluation and genetic integrity assessment of cryopreserved papaya clones. Plant Cell Report 28:1421-1430.

Le Bras C, Le Besnerais PH, Hamama L, Grapin A (2014). Cryopreservation of ex-vitro-grown Rosa chinensis 'Old Blush' buds using droplet-vitrification and encapsulation-dehydration. Plant Cell Tissue and Organ Culture 116:235-242.

Liu Q, Liu Y, Xu J, Cui J, Jia M, Shi Y (2015). Cryopreservation of Chinese old roses (Rosa chinensis Jacq.) shoot tips by vitrification. Propagation of Ornamental Plants 15:35-41.

Lynch PT, Harris WC, Chartier-Hollis JM (1996). The cryopreservation of shoot tips of Rosa multiflora. Plant Growth Regulation 20:43-45.

Marchant R, Power JB, Davey MR, Chartier-Hollis JM, Lynch PT (1993) Cryopreservation of pollen from 2 rose cultivars. Euphytica 66:235-241.

Matsumoto T, Akihiro T, Maki S, Mochida K, Kitagawa M, Tanaka D, Yamamoto S-I, Niino T (2013). Genetic stability assessment of wasabi plants regenerated form long-term cryopreserved shoot tips using morphological, biochemical and molecular analysis. CryoLetters 34:128-136.

Maślanka M, Panis B, Malik M (2016). Cryopreservation of Narcissus L. 'Carlton' somatic embryos by droplet vitrification. Propagation of Ornamental Plants 16(1):28-35.
Milala J, Sójka M, Król K, Buczek M (2013). Charakterystyka składu chemicznego owoców Rosa pomifera 'Karpatia' [Profile of chemical composition of Rosa pomifera 'Karpatia' fruits]. Żywność Nauka Technologia Jakość 5:154-167.

Mubbarakh SA, Izhar NA, Rajasegar A, Subramaniam S (2014). Establishment of encapsulation-dehydration technique for in vitro fragmented explants of Rosa bybrida L. cv. Helmut Schmidt. Emirates Journal of Food and Agriculture 26:565-276.

Murashige T, Skoog F (1962). A revised medium for rapid growth and bioassays with tobacco tissue cultures. Physiologia Plantarum 15:473497.

Nowak R (2005). Fatty acids composition in fruits of wild rose species. Acta Societatis Botanicorum Poloniae 74(3): 229-235.

Panis B, Piette B, Swennen R (2005). Droplet vitrification of apical meristems: a cryopreservation protocol applicable to all Musaceae. Plant Science 168:45-55.

Pati PK, Rath SP, Sharma M, Sood A, Ahuja PS (2006). In vitro propagation of rose-a review. Biotechnology Advances 24:94-114.

Pawłowska B, Bach A (2011) Cryopreservation by encapsulation dehydration of in vitro grown shoot buds of Rosa 'New Dawn'. Acta Horticulturae 908:303-307.

Pawłowska B (2011). The effect of BA and $\mathrm{GA}_{3}$ on shoot multiplication in in vitro cultures of Polish wild roses. Folia Horticulturae 23:145-149.

Pawłowska B, Szewczyk-Taranek B (2014). Droplet vitrification cryopreservation of Rosa canina and Rosa rubiginosa using shoot tips from in situ plants. Scientia Horticulturae 168:151-156.

Pawłowska B, Szewczyk-Taranek B (2015). Efficient cryopreservation by droplet vitrification of pentaploid roses and the phenotype of regenerated plants. Acta Societatis Botanicorum Poloniae 84:439442.

Poisson AS, Berthelot P, Le Bras C, Grapin A, VergneE, Chevreau E (2016). A droplet-vitrification protocol enabled cryopreservation of doubled haploid explants of Malus $\times$ domestica Borkh.Golden Delicious'. Scientia Horticulturae 209:187-191.

Qiu Zhu W, LiHua L, WenXuan, D (2009). Cryopreservation of rose in vitro shoot tips by vitrification. Journal of Shenyang Agricultural University 40:156-159.

Rajasekharan PE, Ganeshan S (1994). Freeze preservation of rose pollen in liquid nitrogen: feasibility, viability and fertility status after long-term storage. Journal of Horticultural Science 69:565-569.

Rout GR, Mohapatra A, Jain SM (2006). Tissue culture of ornamental pot plant: A critical review on present scenario and future prospects. Biotechnology Advances 24:531-560.

Sakai A, Kobayashi S, Oiyama I (1990). Cryopreservation of nucellar cells of navel orange (Citrus sinensis Osb. var. brasiliensis Tanaka) by vitrification. Plant Cell Reports 9(1):30-33.

Sedlák J, Paprštein F (2014). Micropropagation of Rosa pomifera. Acta Horticulturae 1048:215-220.

Souza FVD, Kaya E, de Jesus Vieira L, de Souza EH, de Oliveira Amorim VB, Skogerboe D, Jenderek MM (2016). Droplet-vitrification and morphohistological studies of cryopreserved shoot tips of cultivated and wild pineapple genotypes. Plant Cell, Tissue and Organ Culture 124(2):351-360. 